MECHANICAL VENTILATORS:

\title{
AN ASSESSMENT OF TWO NEW MACHINES FOR USE IN THE OPERATING ROQM*
}

\section{H. BarRie FaIRLeY, M.B., B.S., F.F.A.R.C.S., $\nmid$ anj Douglas D. HuNTER, M.D.}

ThE ESSENTIAL FEATURE of any mechanical ventilator is its ability to ventilate patients with both normal and abnormal lungs, and to do this with a minimum disturbance of cardiovascular function. With regard to the last factor, Cournand 1 provided the classical information on this subject, pointing out that when mean intrathoracic pressure is low, cardiac output will be least disturbed. This situation is most easily created by a ventilatory pattern in which inflation occurs rapidly and expiration is not impeded. However, in competition with this requirement, there is the need to provide as even a pattern of airflow distribution as possible. This will be a relatively unimportant factor in those patients with normal lungs but will assume greater significance in many' patients with pulmonary pathology. Intermittent positive-pressure respiration is always associated with uneven distribution of inspired air and a consequent increase in physiplogical dead space.,2, Abnormalities of distribution will be most exaggerated when the airflow is highest. ${ }^{4}$ Thus, in those patients with abnormal lungs, the need to provide relatively slow inspiratory (and possibly expiratory) How rates will be in direct competition with the ideal wave-form requirements for cardiovascular stability. Considerable latitude with regard to both aspects exists in the majority of cases. However, in the more severe problems, a compromise will have to be struck and this will be facilitated by the use of versatile equipment, capable of flow-rate adjustment and predicțable ventilatory performance. The actual ventilation provided will be dependent upon the interrelationship of four variables: volume, pressure, flow, and ráte or frequency. Changes in these four variables, in response to changes in resistance in the patient-respirator circuit, will determine the degree of constancy of performance of any given ventilator. The theoretical aspects of this subject have recently been outlined by Mapleson. ${ }^{5}$

Two new operating room ventilators have been assessed clinically and their response to changes in resistance have been quantitated in the laboratory. They are the Air-Shields Ventimeter Ventilator (Fig. 1) and the prototype of a new anaesthesia ventilator, to be marketed by Ohio Chemical Canada Ltd. (standard and deluxe models) (Fig. 2). Each is capable of volume constancy and, with the exception of the Ohio standard model, flow variability. The Ohio standard model has no negative phase setting. These ventilatoss have been compared with the Bird Mark 8 and Mark 4 combination, which provides similar potentials.

\footnotetext{
'From the Department of Anaesthesia, Toronto General Hospital, and the Anaesthesia Research Laboratory, University of Toronto, Toronto, Ontario.

† Assisted by a grant from the Connaught Trust Endowment Fund.

\$M.R.C. Research Assistant.
} 


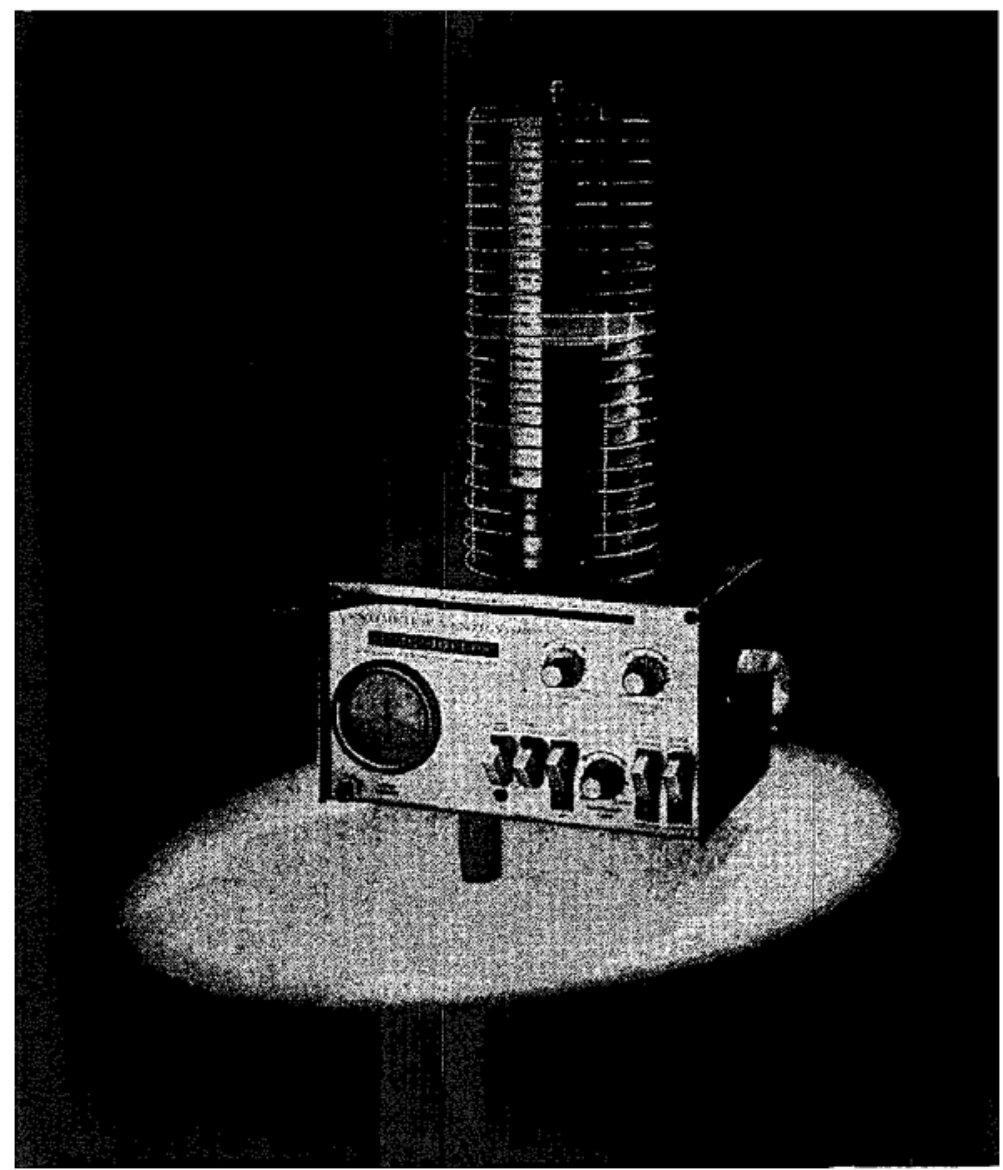

Frgune 1. Air-Shields Ventimeter Ventilator. Bag mount protruding below.

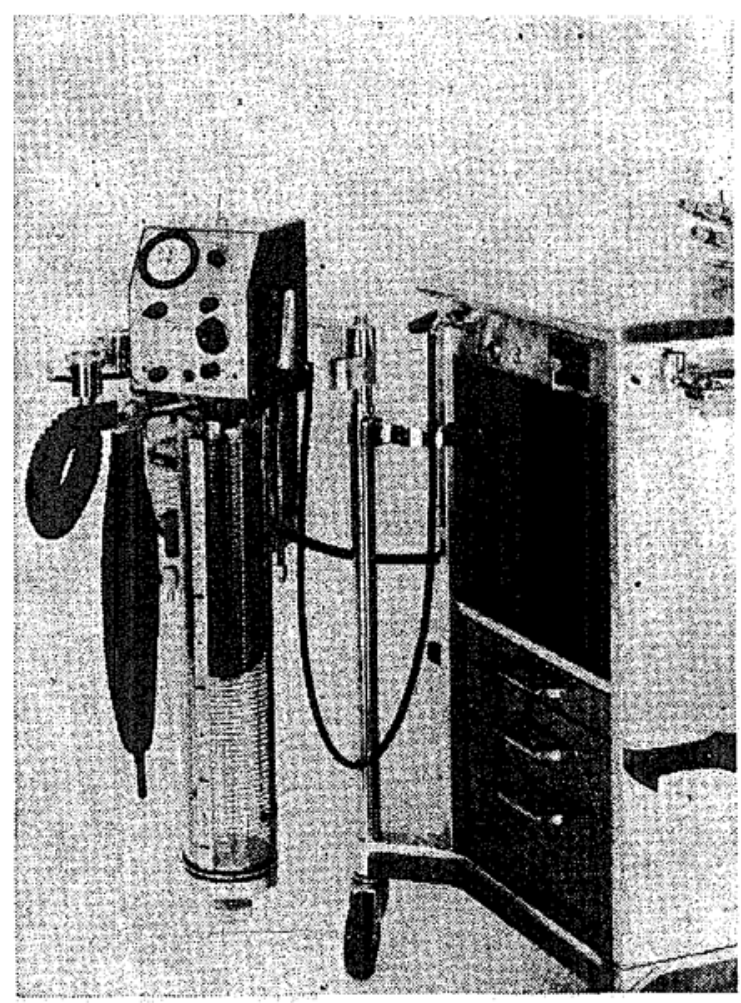

(a)

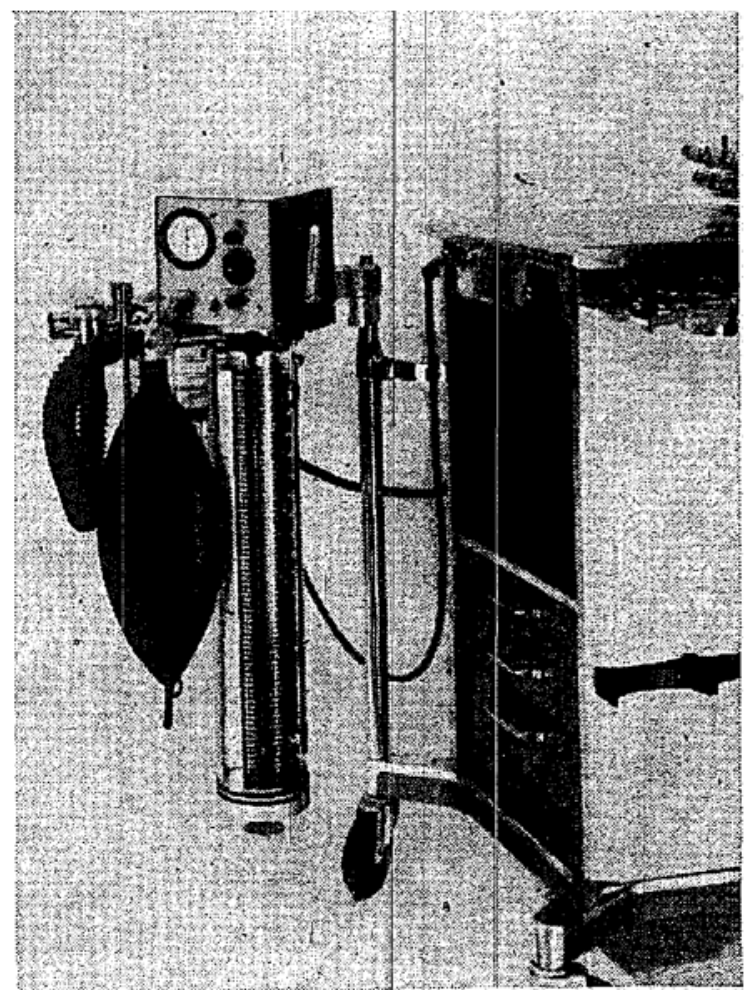

(b)

Frgure 2. (a) Ohio deluxe Anaesthesia Ventilator. (b) Ohio Standard Anaesthesia Ventilator. 


\section{LABORATORY STUDY}

An artificial lung-thorax was constructed from four 4-gallon flasks, joined in series by short lengths of wide-bore tubing. This system has a static compliance of $0.108 \mathrm{~L} . / \mathrm{cm} . \mathrm{H}_{2} \mathrm{O}$, which may be subdivided by clamping the connecting tubing. In this study, the function of the respirators was examined at full and half compliance. The input tube (trachea) for this system can be intubated with endotracheal tubes of varying size, to simulate changes in airflow resistance. Two resistances were employed in this series of measurements: a 9.5-mm. tube with a resistance of $2.2 \mathrm{~cm} . \mathrm{H}_{2} \mathrm{O} / \mathrm{L}$. $/ \mathrm{sec}$. and a $4-\mathrm{mm}$. tube with a resistance of $16.5 \mathrm{~cm}$. $\mathrm{H}_{2} \mathrm{O} / \mathrm{L}$./sec. Both resistances are quoted at $1 \mathrm{~L} . / \mathrm{sec}$. and the change from one to the other constitutes an increase in resistance of 7.43 times.

A standard Ohio circle system with a Roswell Park absorber was connected to the endotracheal tube and the ventilator under test was connected to the rebreathing bag mount. All tubing used was made of non-expanding plastic material. In each instance, a continuous gas flow of 6 litres of nitrous oxide and 3 litres of oxygen was passed into the circle in the usual way. This was in an attempt to simulate normal clinical circumstances, recognizing that many ventilators function indifferently with high anaesthetic gas flows.

Respiratory airflow wás detected by a Fleisch No. 2 pneumotachograph and a Statham PM5 differential transducer, calibrated for nitrous oxide: bxygen mixtures in a proportion of 2:1. This was placed between the circle Y-piece and the endotracheal tube.

Pressure changes were detected by a Statham PR23 transducer, calibrated with a water manometer and connected distal to the pneumotachograph.

Tidal volumes were obtained by electrical integration of airflow, using a Grass U1-1 integrator.

Each parameter was recorded continuously on a Grass Polygraph.

Thus, an anaesthetic circuit closely simulating normal circumstances was established. Each ventilator was set to deliver $700 \mathrm{ml}$. as close to 15 times per minute as possible and the following observations were made. (Considerable difficulty was encountered in achieving exact volumes and rates, particularly where controls were interrelated. This was especially the case with the Bird A/C (assistor/controller combination).)

\section{Pressure, Airflow, and Volume Wave Form Charadteristics}

The wave forms produced by each ventilafor are shown in Figures 3-10.

The Air-Shields Ventimeter Ventilator is a constant-flow generator, according to Mapleson's classification. It has the advantage of providing an ideal pressure wave form and the possible disadvantage of maintaining a high airflow at endinspiration. It is capable of creating a definite persistent negative pressure at the airway.

The Ohio machines provide a more rounded inspiratory airflow contour, giving the advantage of falling airflows at end-inspiration but the disadvantage of sustained end-inspiratory pressures. This distinction was more obvious at the higher resistances. 


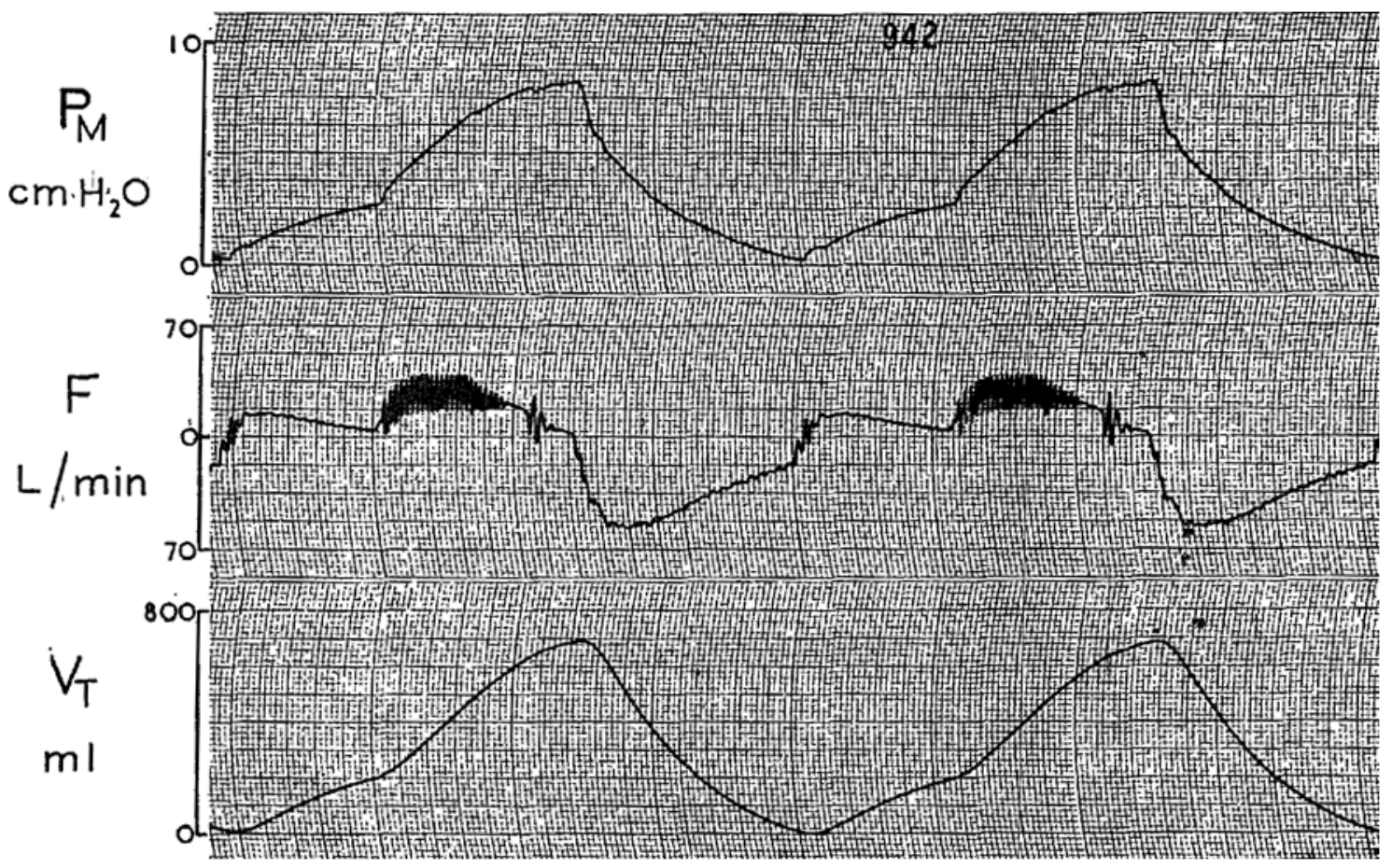

FIGURE 3. Bird A/C (Mark 8 and Mark 4 combination) without air entrainment. I.P.P. with maximum flow rate. $: P_{M}=$ Pressure at mouth level, $F=$ airfl $\phi w_{1}, V_{T}=$ tidal volume, paper speed $=25 \mathrm{~mm} . / \mathrm{sec}$.

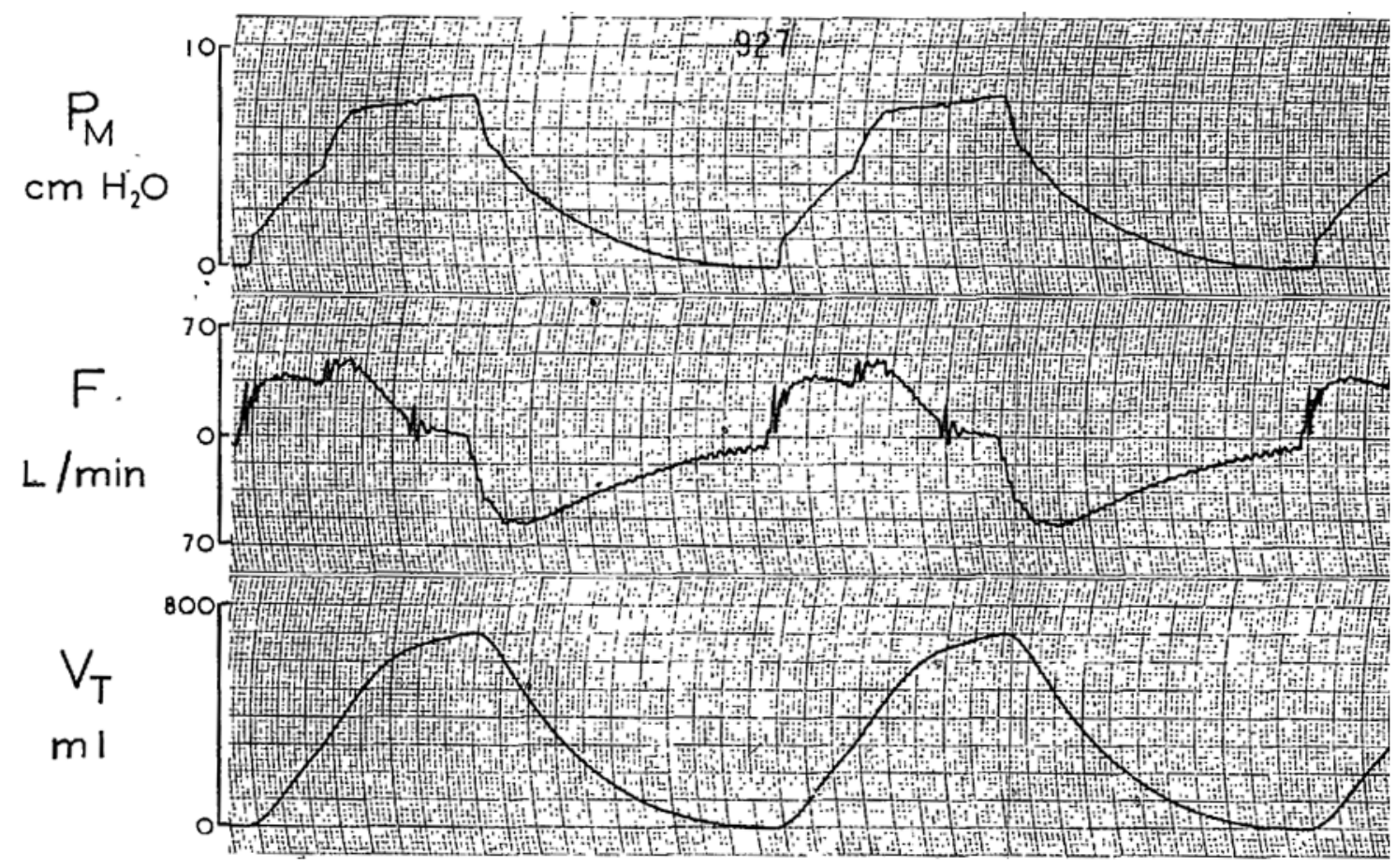

FIGURE 4. Bird A/C with air entrainment. I.P.P. with maximum flow rate. 


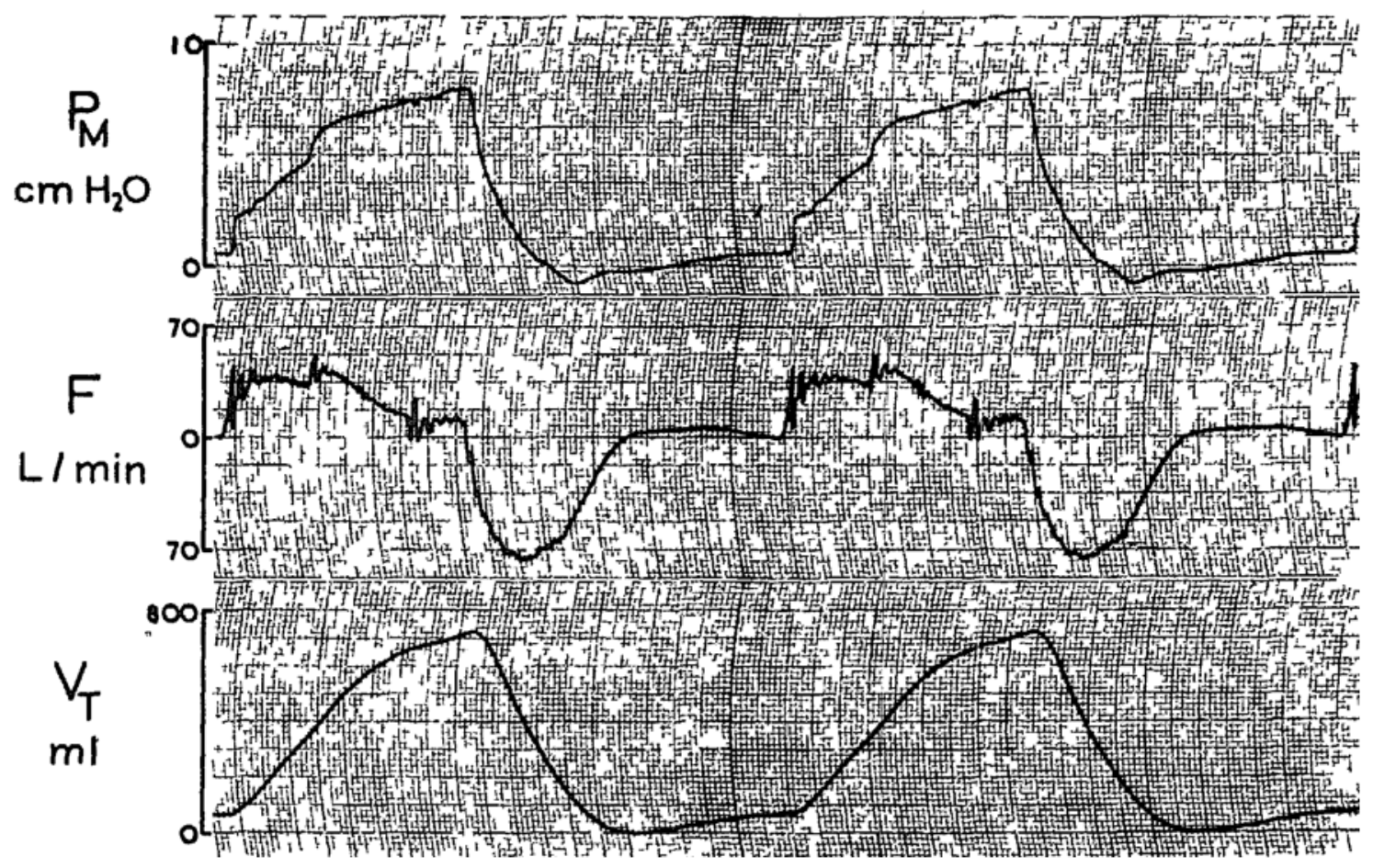

Figure 5. Bird A/C with maximum negative pressure trom Mark 8.

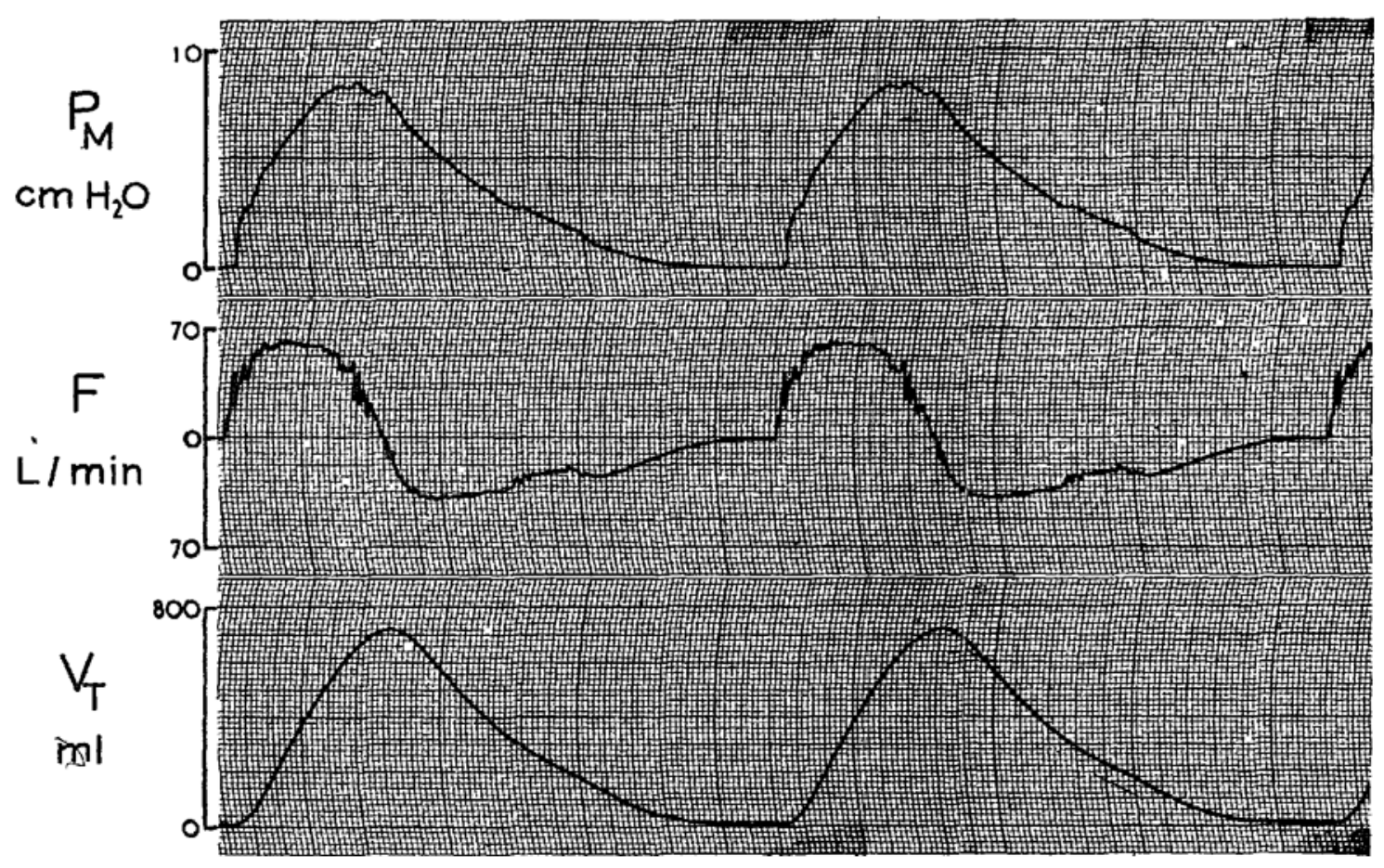

Frgure 6. Ohio deluxe Anaesthesia Ventilator. I.P.P. with flow rate set at $60 \mathrm{~L} . / \mathrm{min}$. 


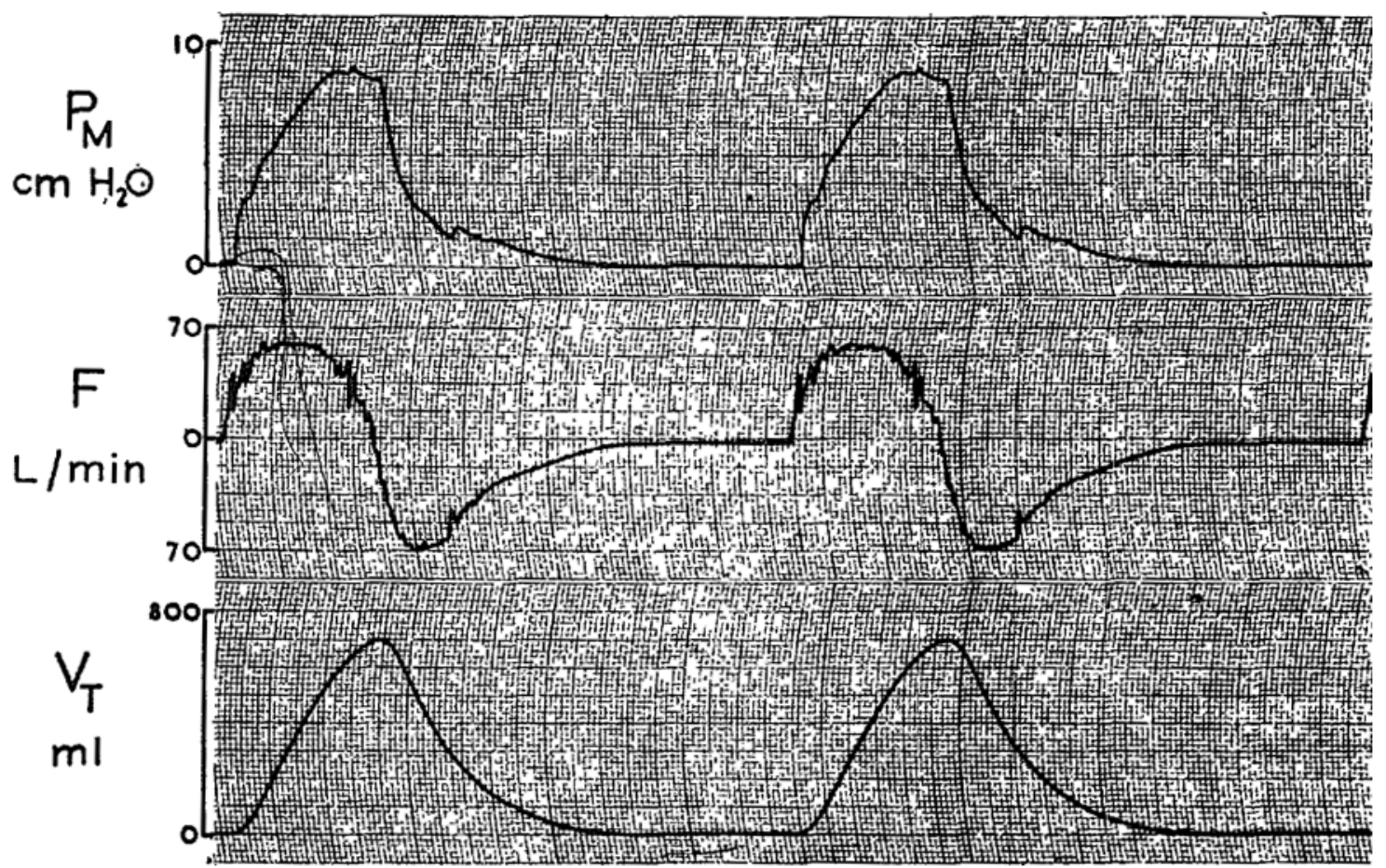

Figuike 7. Ohio Deluxe Anaesthesia Ventilator, with maximum negative pressure setting.

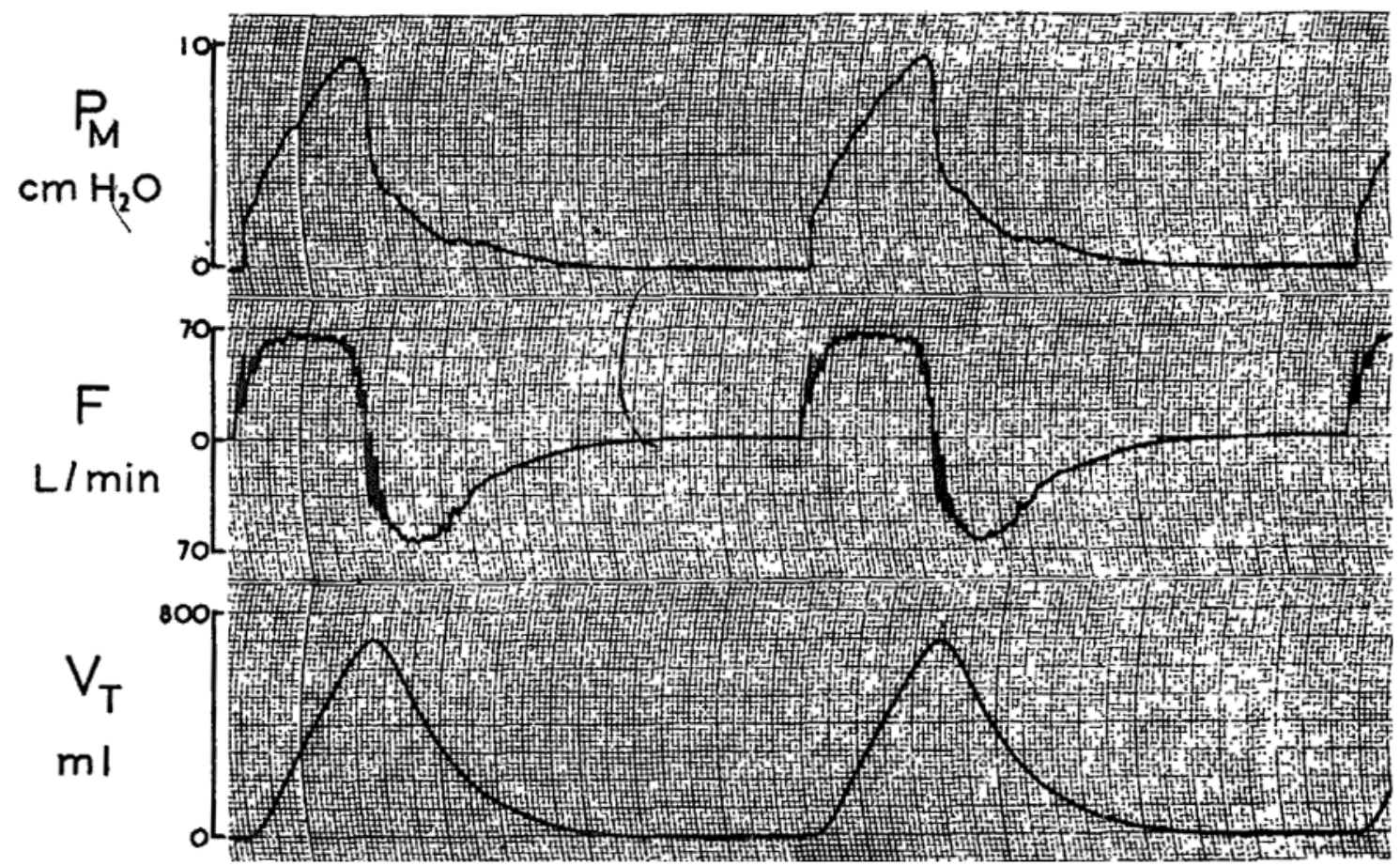

FIGURE 8. Ohio standard Anaesthesia Ventilator. 


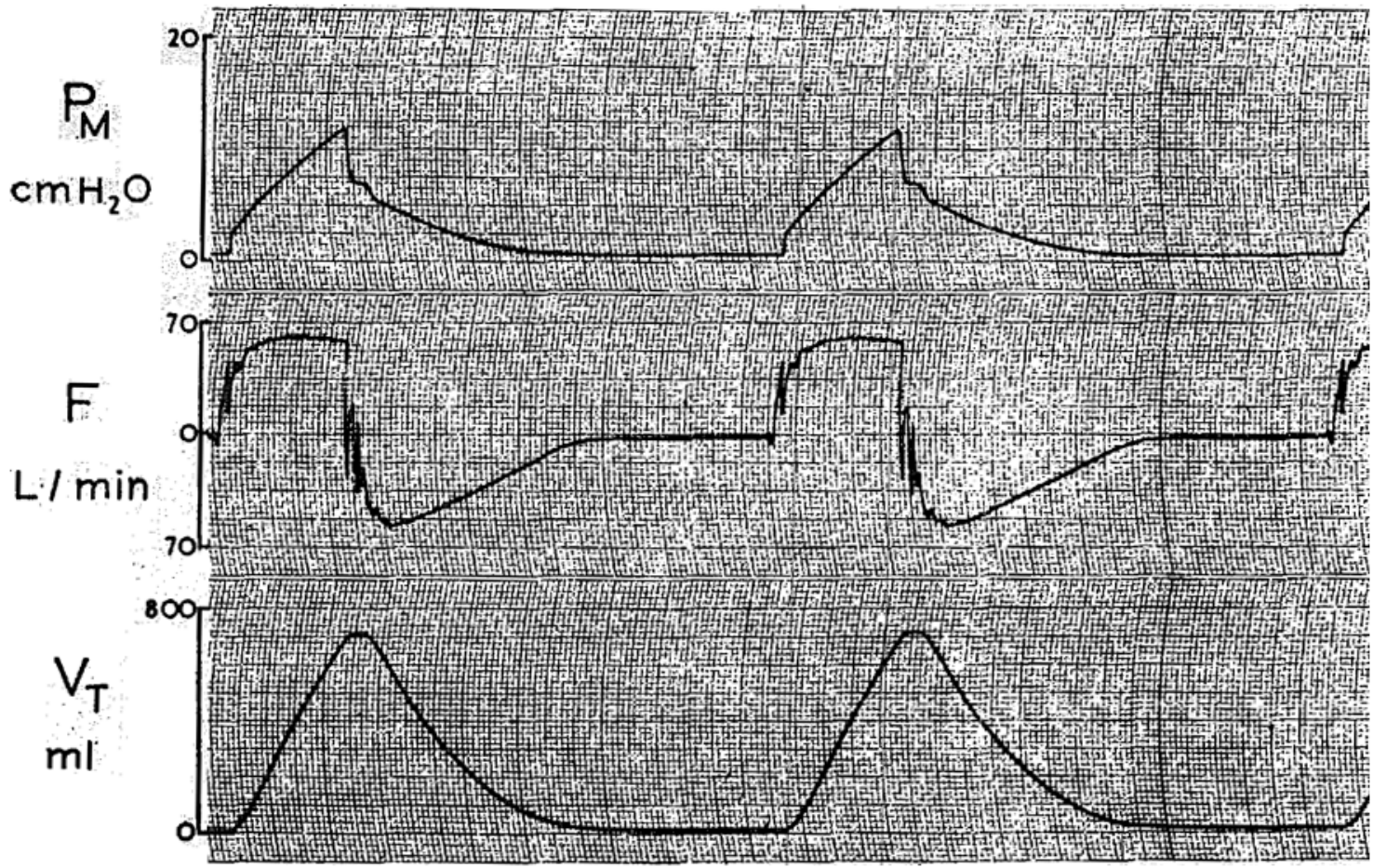

Figune 9. Air-Shields Ventimeter Ventilator. I.P.P. with maximum flow rate. N.B. Pressure sensitivity is half that used for other ventilators.

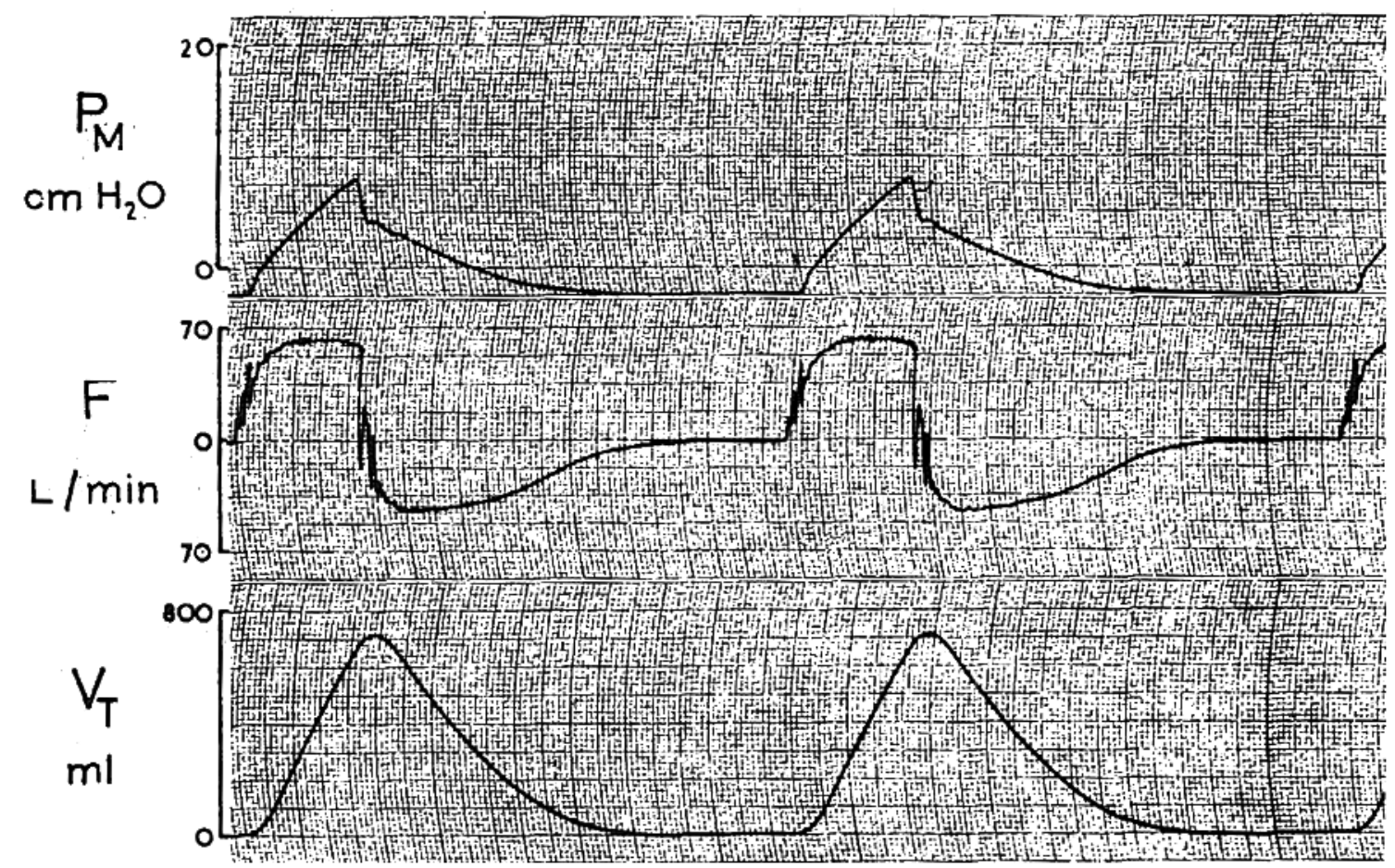

Figure 10. Air-Shields Ventimeter Ventilator, with negative phase. N.B. Pressure sensitivity is half that used for other ventilators. 
The early expiratory flow produced by the deluxe model was slower than that provided by the standard, with less favourable expiratory pressure contour. The negative phase could be used to offset this but was insufficiently powerful to create significant negativity at the airway.

The Bird $\cdot A / C$ gave the least favourable pressure contour. In order to provide volume-limiting (pressure variable) it was necessary to set the pressure on the Mark 8 driving unit well above that required at the Mark 4. This gave a sustained end-inflation period. Inspiratory flow and pressure curves show a step at the point where the excess gas blow-off valve closes. End-inflation flows were favourably low, particularly with air entrainment. Significant negativity could not be achieved at the airway-a striking difference between the Mark 8 when used alone and when used in conjunction with the Mark 4 unit.

2. Response to Doubling the Elastic Resistance of the Artificial Lung-Thorax, at Various Peak Inspiratory Airflows

Each ventilator was set to deliver $700^{\circ} \mathrm{ml}$. tidal volume as close to $15^{\circ}$ times per minute as possible. The ventilator settings were left constant and only the resistance changed.

TABLE I

\begin{tabular}{|c|c|c|}
\hline & Compliance $\times 1$ & Compliance $\times 0.5$ \\
\hline $\begin{array}{l}\text { Bird A/C with ventur } \\
\text { Volume, ml. } \\
\text { Flow, L./min. } \\
\text { Insp./exp., sec. }\end{array}$ & $\begin{array}{c}710 \\
30 \\
2 \quad 68 / 1 \quad 62\end{array}$ & $\begin{array}{l}620 \\
27 \\
3 / 1 \quad 36\end{array}$ \\
\hline $\begin{array}{c}\text { Bird A/C, without ve } \\
\text { Volume, ml. } \\
\text { Flow, L./min. } \\
\text { Insp./exp., sec. }\end{array}$ & $\begin{array}{lll} & & \\
& 720 & \\
& 27 & \\
& & \\
2 & 60 / 2 & 92\end{array}$ & $\begin{array}{cc} & 610 \\
& 27 \\
2 \quad 28 / 2 & 92\end{array}$ \\
\hline $\begin{array}{l}\text { Ohio deluxe } \\
\text { Volume, ml. } \\
\text { Flow, L./min. } \\
\text { Insp./exp, sec. }\end{array}$ & 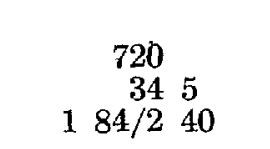 & $\begin{array}{rl}630 \\
34 & 5 \\
1 \cdot 68 / 2 & 44\end{array}$ \\
\hline $\begin{array}{l}\text { Air-Shields } \\
\text { Volume, ml. } \\
\text { Flow, L./min. } \\
\text { Insp./exp., sec. }\end{array}$ & $\begin{array}{c}700 \\
30 \\
1 \quad 48 / 260\end{array}$ & 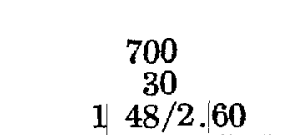 \\
\hline
\end{tabular}

Tables I-III show the tidal volume, peak flow rate, and inspiration/expiration time ratio responses of various groups of ventilators to a change of resistance. Ventilators were allocated to each group according to their flow capabilities, when used in the manner described. Thus, the Bird A/C was incapable of flows above $27 \mathrm{~L} . / \mathrm{min}$., without air entrainment, and above $47.5 \mathrm{~L} . / \mathrm{min}$. with air entrainment. Only the Ohio deluxe machine would deliver flows over $60 \mathrm{~L} . / \mathrm{min}$. Grouping according to peak flows is somewhat crude, owing to the limitations of each machine in delivering the exact flow required for the study.

\section{Response to a Sevenfold Increase in Airflow Resistance}

Each ventilator was set to deliver $700 \mathrm{ml}$. as close to 15 times per minute as possible. The ventilator controls were left constant as was the simulated lung- 
TABLE II

Volume-Limiting (60-L./min. peak flow, 9.5-imm. tube)

\begin{tabular}{lcc}
\hline & Compliance $\times 1$ & Compliance $\times 0.5$ \\
\hline Bird A/C with venturi & & \\
Volume, ml. & 710 & 620 \\
Flow, L./min. & 47.5 & 173.5 \\
Insp./exp., sec. & $1.84 / 2.52$ & $172 / 2.52$ \\
Ohio deluxe & & \\
Volume, ml. & 700 & 680 \\
Flow, L./min. & 585 & 58.5 \\
Insp./exp., sec. & $108 / 3.0$ & $1 \mid 0 / 3.04$ \\
Ohio standard & & \\
Volume, ml. & 710 & 700 \\
Flow, L./min. & 68 & 68 \\
Insp./exp., sec. & $096 / 3.00$ & $100 / 296$ \\
Air-Shields & & \\
Volume, ml. & 700 & 700 \\
Flow, L./min. & 58 & 58 \\
Insp./exp., sec. & $0.96 / 3.04$ & $096 / 304$ \\
\hline
\end{tabular}

TABLE III

Volume-Limiting (90-L./min. peak flow, 9.5-mm. tube)

\begin{tabular}{lcc}
\hline & Compliance $\times 1$ & Compliance $\times 0.5$ \\
\hline Ohio deluxe & & \\
Volume, ml. & 710 & 700 \\
Flow, L./min. & 74 & 74 \\
Insp./exp., sec. & $0.92 / 3.16$ & $0 \quad 92 / 2.84$ \\
\hline
\end{tabular}

TABLE IV

Volume-Limiting (30-L./min. peak flow, cônpliance $\times 1$ )

\begin{tabular}{lcc}
\hline & Resistance $\times 1$ & Resistance $\times 7.43$ \\
\hline Bird A/C with venturi & & \\
Volume, ml. & 710 & 600. \\
Flow, L./min. & 30 & 23 \\
Insp./exp., sec. & $2.68 / 1.62$ & $3.04 / 1.76$ \\
Bird A/C without venturi & 720 & \\
Volume, ml. & 27 & 640 \\
Flow, L./min. & $260 / 292$ & $2.52 / 2.96$ \\
Insp./exp., sec. & & \\
Ohio deluxe & 720 & 670 \\
Volume, ml. & 34.5 & 27 \\
Flow, L./min. & $1.84 / 2.40$ & $188 / 2$ \\
Insp./exp., sec. & & \\
Air-Shields & 700 & 680 \\
Volume, mI. & 30 & 30 \\
Flow, L./min. & $1.48 / 2.60$ & $1.48 / 2.60$ \\
Insp./exp., sec. &
\end{tabular}

thorax compliance $\left(0.108 \mathrm{~L} . / \mathrm{cm} . \mathrm{H}_{2} \mathrm{O}\right.$ ). By changing the size of the endotracheal tube, the resistance was increased 7.43 times. Each of the above groups was studied, with regard to the effect of this resistance change (Tables IV-VI). 
TABLE V

Volume-Limiting (60-L./min. peak flow, compliance $\times 1$ )

\begin{tabular}{lcc}
\hline & Resistance $\times 1$ & Resisţance $\times 7.43$ \\
\hline Bird A/C with venturi & & \\
Volume, ml. & 710 & 640 \\
Flow, L./min. & 475 & 36 \\
Insp./exp., sec. & $184 / 252$ & $2.0 / 26$ \\
Ohio deluxe & & \\
Volume, ml. & 700 & 715 \\
Flow, L./min. & 585 & 49 \\
Insp./exp., sec. & $1.08 / 30$ & $184 / 2.08$ \\
Ohio standard & & \\
Volume, ml. & 710 & 720 \\
Flow, L./min. & 68 & 57 \\
Insp./exp. sec. & $096 / 300$ & $1+28 / 252$ \\
Arr-Shrelds & 2 & \\
Volume, ml. & 700 & 650 \\
Flow, L./min. & 58 & 55 \\
Insp./exp, sec. & $096 / 304$ & $0.96 / 304$ \\
\hline
\end{tabular}

TABLE VI

Volume-Limiting $(90-\mathrm{L} . / \mathrm{min}$. peak flow, compliance $\times 1$ )

\begin{tabular}{lcc}
\hline & Resistance $\times 1$ & Resistance $\times 743$ \\
\hline Ohio deluxe & & \\
Volume, m1 & 710 & 720 \\
Flow, L./min. & 74 & 57 \\
Insp./exp., sec. & $092 / 316$ & $152 / 196$ \\
\hline
\end{tabular}

Response of respirator performance to increases in resistance may be summarized as follows.

\section{Volume-Limiting}

Tidal volume. The Air-Shields and Ohio equipment each showed relatively good tidal volume constancy, the former functioning slightly betler at low flows and the latter at high flows. The Bird $\mathrm{A} / \mathrm{C}$ gave a consistent fall in tidal volume as resistance increased. This feature was worse when air entrainment was employed.

Peak inspiratory flow rates. The Air-Shields machine gave constant flows under all circumstances except at the maximum flow setting with sevenfold increase in airflow resistance. Even at this point the fall in flow was small. The Ohio machines maintained flows in the face of compliance change but showed a fall at high flow settings, with a sevenfold increase in airflow resistance. The Bird A/C maintained peak How when no air entrainment was employed but permitted a fall when air entrainment was used to provide the higher flow rảtes.

Inspiration/expiration timing. Each machine functions differently in this regard. The Air-Shields timing remained absolutely constant. Thus, any fall in flow would result in a fall in both tidal and minute volume. The Ohio equipment gave rela- 
tively constant respiratory rates. When flow fell, inspiration would lengthen, tending to maintain tidal volume. A reciprocal shortening of expiration tended to maintain the respiratory rate and therefore the minute volume. However, this could ultimately give inspiration/expiration ratios greater than unity, in the face of high thoraco-pulmonary resistances. The respiratory rate in the Bird equipment is adjusted by setting the length of the expiratory phase. However, the rate is also determined by the length of inspiration, which is a function of a number of variables, such as the pressure set on the Mark 8 driving unit, the flow of anaesthetic gases, and the inspiratory airflow response to changing resistances. At best, this machine is pressure-cycled, even though volume-limiting is applied, and it provides quite variable inspiration/expiration ratios.

In response to changing resistances, then, the Air-Shields Ventimeter Ventilator maintains a constant respiratory rate and inspiration/expiration time ratio. Minute volume will only be reduced should flow fall. These studies suggest that this will only occur with relatively great increases in resistance. The Ohio Anaesthesia Ventilators maintain a relatively constant respiratory rate and minute volume, with a varying inspiration/expiration time ratio. In the circumstances of this study, this equipment tended to increase minute volume with increased resistance. The Bird A/C, used with volume-limiting, was not as satisfactory as the others in maintaining constant ventilation in the face of changing resistances.

\section{Pressure-Limiting}

It is not the purpose of this study to give detailed consideration to the use of machines with a pressure-limited, volume-variable setting. However, Tables VII-XII give figures for the performance of the Bird and Ohio equipment under

TABLE VII

Pressure-Limiting (30-L./min. peak flow, 9.5-mm tube)

\begin{tabular}{lcc}
\hline & Compliance $\times 1$ & Compliance $\times 0.5$ \\
\hline Bird A/C with venturi & & \\
Volume, ml. & 690 & 440 \\
Flow, L./min. & 345 & 27 \\
Insp./exp, sec. & $20 / 16$ & $1.72 / 1.32$ \\
Bird A/C without venturi & & \\
Volume, ml. & 730 & 480 \\
Flow, L./min. & 30 & 27 \\
Insp./exp., sec. & $252 / 160$ & $1.92 / 1.40$ \\
Ohio deluxe & & \\
Volume, ml. & 700 & 430 \\
Flow, L./min. & 30 & 30 \\
Insp./exp., sec. & $184 / 2.06$ & $108 / 2.40$ \\
\hline
\end{tabular}

such circumstances. The Air-Shields Ventimeter Ventilator is incapable of this form of operation.

Each machine showed a significant alteration in tidal volume when used in this manner. 
TABLE VIII

Pressure-Limiting (60-L./min. peak flow, 9.5-mm./ tubè)

\begin{tabular}{lcc}
\hline \hline & Compliance $\times 1$ & Compliance $\times 0.5$ \\
\hline Bird A/C with venturi & & \\
Volume, ml. & 710 & 480 \\
Flow, L./min. & 42 & 30 \\
Insp./exp., sec. & $18 / 268$ & $152 / 268$ \\
Ohio deluxe & & \\
Volume, ml. & 740 & 440 \\
Flow, L./min. & 48 & 48 \\
Insp./exp., sec. & $156 / 232$ & $088 / 2.44$ \\
Ohio standard & & \\
Volume, ml. & 740. & 420. \\
Flow, L./min. & $57^{\circ}$ & 57 \\
Insp/exp., sec. & $152 / 276$ & $088 / 288$ \\
\hline
\end{tabular}

TABLE IX

Pressure-Limiting (90-L./min. peak flow, 9.5 -mm. tube)

\begin{tabular}{lcc}
\hline \hline & Compliance $\times 1$ & Compliance $\times 0.5$ \\
\hline Ohio deluxe & & \\
Volume, ml. & 700 & 400 \\
Flow, L $/ \mathrm{min.}$ & 53 & 53 \\
Insp./exp., sec. & $\mathbf{1} 52 / 224$ & $084 / 3$ ob \\
\hline
\end{tabular}

TABLE $X$

Pressure-Limiting (30-L./min. peak flow, compliance $\times 1)$

\begin{tabular}{lcc}
\hline & Resistance $\times 1$ & Resistance $\times 7.43$ \\
\hline Bird A/C with venturi & & \\
Volume, ml. & 690 & \multicolumn{2}{c}{400} \\
Flow, L./min. & 345 & 30 \\
Insp./exp., sec. & $20 / 16$ & $164 / 156$ \\
Bird A/C without ventur. & & \multicolumn{2}{c}{} \\
Volume, ml. & 730 & \multicolumn{2}{c}{450} \\
Flow, L./min. & 30 & 27 \\
Insp./exp., sec. & $252 / 160$ & $188 / 156$ \\
Ohio deluxe & & \multicolumn{2}{c}{500} \\
Volume, ml. & 700 & 30 \\
Flow, L./min. & 30 & 30 \\
Insp./exp., sec. & $184 / 206$ & $184 / 156$ \\
\hline
\end{tabular}

\section{Volume Calibration}

The Ohio machines are calibrated in 100-ml. increments to $500 \mathrm{ml}$; then in $250-\mathrm{ml}$. increments to $2000 \mathrm{ml}$. It might be advantageous to have the $100-\mathrm{ml}$. increments to $1000 \mathrm{ml}$. The Air-Shields machine is calibrated in 100-ml. increments to $1500 \mathrm{ml}$. The Ohio machine's calibration proved accurate dùring intermittent positive-pressure ventilation, whereas the Air-Shields scale was less applicable. This scale was accurate under static circumstances but, when the 
TABLE XI

PRessure-Limitrng (60-L./min. peak flow, compliance $\times 1$ )

\begin{tabular}{ccc}
\hline & Resistance $\times 1$ & Resistance $\times 7.43$ \\
\hline Bird A/C with venturi & & \\
Volume, ml. & 710 & 490 \\
Flow, L./min. & 42 & 34.5 \\
Insp./exp., sec. & $18 / 268$ & $156 / 268$ \\
Ohio deluxe & & \\
Volume, ml & 740 & 480 \\
Flow, L/min. & 48 & 30 \\
Insp /exp, sec. & $156 / 232$ & $156 / 1.72$ \\
Ohio standard & & \\
Volume, ml. & 740 & 550 \\
Flow, L./min. & 57 & 38 \\
Insp /exp, sec. & $152 / 276$ & $172 / 196$ \\
\hline
\end{tabular}

TABLE XII

Pressure-Limrting $(90-\mathrm{L} . / \mathrm{min}$. peak flow, complance $\times 1$ )

\begin{tabular}{lcc}
\hline & Resistance $\times 1$ & Resistance $\times 7.43$ \\
\hline Ohio deluxé & & \\
Volume, ml. & 700 & 500 \\
Flow, L /min. & 53 & 345 \\
Insp./exp, sec. & $152 / 224$ & $220 / 156$ \\
\hline
\end{tabular}

ventilator was delivering $700 \mathrm{ml}$. fifteen times per munute against a normal compliance and airflow resistance, the ventimeter registered a tidal volume of $900 \mathrm{ml}$. This is probably due to the relatively flimsy material of which the bellows is made and the rigid inspiration phase duration, causing bellows expansion. The Ohio machine's bellows is less expansile and the inspiratory phase less rigidly timed, probably accounting for the more reliable volume calibration. The tidal volume indicator on the Bird Mark $\wedge 4$ was not at all accurate when not using a completely closed system.

\section{Flow Calibration}

Only the Ohio deluxe Anaesthesia Ventilator has a calibrated flow control. This was accurate only when the machine was working against a stated fixed resistance. However, in practice, this resistance will rarely be present and variations in flow from the stated values were substantial. This scale is considered a misleading embellishment, better replaced by an uncalibrated scale, as with the other machines.

\section{Operating Room Exaluation}

In practice all three machines functioned very satusfactorily. Each has its advantages and disadvantages.

Motive force. All three are driven by compressed gas. The Air-Shields machine requires $35 \mathrm{lb} . / \mathrm{sq}$. in. driving pressure and incorporates a regulating valve to 
provide this. The Bird and Ohio ventilators require approximately $50 \mathrm{lb} . / \mathrm{sq}$ : in. The Air-Shields machine does not incorporate a venturi in its positive-pressure phase. The Bird need not, if only low flows are required. The Ohio and the Bird respirators utilize air entrainment (the latter if flows above $27 \mathrm{~L} . / \mathrm{min}$. are required) and this probably accounts for some reduction in airflow at high resistances.

Function with leaks. Under circumstances where a considerable air leak exists, such as with a burst endotracheal tube cuff or a bronchial leak during pulmonary surgery, a pressure-constant system with a high flow rate is advanitageous. Only the Ohio deluxe machine provides this. Unless the leak is constant (i.e. a fixed aperture and a constant parallel resistance-which is unlikely during the course of a surgical procedure), a flow and volume constant system may not be satisfactory. This is felt to be one of the few disadvantages of the Air-Shields Ventimeter Ventilator.

Monitoring of volume and pressure. Measurements taken at a respirator will be no substitute for those taken at the airway, with equipment such as the Wright anemometer. However, the monitoring possibilities of the three types of respirator were examined and found to vary considerably. Only the Air-Shields Ventimeter Ventilator will indicate the extent of spontaneous respiration and this proved most useful in practice. This machine also has the advantage of indicating circuit pressure, measured at mouth level. The Ohio machines were very accurate in their indication of tidal volume during intermittent positive pressure, as opposed to the Air-Shields equipment, which showed a variable error. The Bird A/C was deficient in that it provided no satisfactory index of the, extent of either spontaneous or controlled respiration.

Function at high anaesthetic gas flows. All three machines function well with minute volumes of anaesthetic gases being introduced continuously into the circuit. However, the excess gas blow-off incorporated into the Bird Mark 4 produced a noticeable variation in its pressure-volume characteristics.

Automatic bag filling. Only the Bird Mark 4 incorporates a device which will fill the bellows with oxygen should the anaesthetic gases run out. This functions only in the pressure-limited setting.

Manual alternative. Each ventilator includes a rebreathing bag alternative, each with its own attraction. The Bird A/C incorporates a useful expiratory valve with its rebreathing bag mount. This may be "permanently" set and is a great advantage in a machine designed for volume constancy, which ejects excess gases from the ventilator itself. Thus, when the circuit is changed back from manual to automatic control, no'valve is open in the circuit. With the Ohio machine, a valve must be opened in the circuit when manual control is started. Should one neglect to close this on returning to the automatic setting, serious underventilation may occur. An interesting feature of the Ohio machine is the detachability of the whole rebreathing bag mount, giving useful mobility when giving manual ventilation. The same mobility could be achieved with the other machines by adding a length of corrugated tubing to the rebreathing bag mount. The Air-Shields machine is unique in that the manual control ${ }^{3}$ bag is not in continuity with the anaesthetic circuit. It is filled from the driving source and 
is connected to the outside of the ventimeter bellows, which itself constitutes the rebreathing bag. This should be a distinct advantage during closed-circuit anaesthesia, when "flushing" the bag will not alter the concentration of anaesthetic gases in the circuit.

Physical features. The two new ventilators are both less bulky than the Bird combination and have all controls on the front (with the exception of the sensitivity control on the Ventimeter Ventilator). The mounting equipment for the Air-Shields machine is more "universal" than that provided with the Ohio ventilators. The latter can easily be corrected, however. The Bird $\mathrm{A} / \mathrm{C}$ has proved most difficult to "mount satisfactorily on the anaesthetic machine. The Ohio machines have a "clean" and "dirty" circuit, so to speak. Thus, the whole breathing circuit can easily be removed from the other working parts for cleaning and sterilization. All three machines were relatively noisy, in keeping with most compressed gas equipment functioning with high motive pressures. The Bird $\mathrm{A} / \mathrm{C}$ was particularly noisy when used with a negative phase.

Patient-triggering. Each of these machines can be triggered by the patient. While the authors doubt the desirability of this in operating room machines, it should be noted that each is basically very sensitive in this regard. However, the Air-Shields ventilator is different in sensing the patient's respiratory effort at mouth level. Unfortunately, the only adaptor provided for this purpose is the international $15-\mathrm{mm}$. size and will not fit many existing connectors.

Conversion for respiratory insufficiency. A possible advantage, for the smaller hospital, is the adaptability of the Bird combination for treating respiratory insufficiency, using the Mark 8 unit. The other machines are not designed for this purpose and would require some modification in the way of gas supply, humidifcation, and non-return valve.

Long-term reliability. Only the Bird unit has had the opportunity to stand the test of time. However, the others are produced by well-known and experienced firms. They appear well engineered and there is no reason to suppose that they will not prove reliable.

In summary, two new mechanical ventilators for use in the operating room, the Air-Shields Ventimeter Ventilator and the Ohio Anaesthesia Ventilator, have been assessed in the laboratory and in the operating room. Both provide volume constancy and flow variability with acceptable efficiency and offer -a'useful contribution to our anaesthesia armamentarium.

\section{RÉSUMÉ}

Nous avons fait l'essai, au laboratoire et dans le salle d'opération, de deux nouveaux ventilateurs à volume constant, débit variable. Ils sont construits pour être utilisés au cours de la chirurgie et nous les avons comparés avec l'association des Bird Mark IV et Mark VIII. Nous avons fait des comparaisons entre les cowrbes de pression, de débit et de volume des trois machines. Nous avons porté attention à l'effet, sur l'air courant, de l'augmentation du débit et de la résistance élastique; nous avons également étudié la vitesse de circulation de l'air et le rapport entre la durée de l'inspiration et celle de l'expiration. 
Les deux appareils peuvent donner une bonne constance de volume ẹn. dépit de l'augmentation des résistances; il s'agit du ventilateur "Air-\$hields Ventimeter" et du ventilateur "Ohio prototype Anesthesia."

\section{REFERENCES}

1. Courin-And, A.; Motley, H. L.; Werko, L.; \& Richards, D. W. J' 'Physiological Studies on the Effects of Intermittent Positive Pressure Breathing on Cardiac Output in Man. Am. J. Physiol. 152: 162 (1948).

2. Campbelt, E. J. M.; Nunn, J. F.; \& Peckett, B. W. A Comparison of Artificial and Spontaneous Respiration with Particular Reference to Ventilation-Blood Flow Relationships. Brit. J. Anaesth. 30: 166 (1958).

3. Watson, W. E. Observations on Physiological Deadspace during /Intermittent Positive Pressure Respiration. Brit. J. Anaesth. 34: 502 (1962).

4. Otis, A. B.; McKerrow, C. B.; Bartlett, R. A.; Mead, J.; Ḿcllkoy, M. B.; SelverSTONE, N. J.; \& RADFond, E. P. Mechanical Factors in Distribution of Pulmonary Ventilation. J. Appl. Physiol. 4: 427 (1956).

5. Mapleson, W. W. The Effect of Changes in Lung Characteristics on the Functioning of Automatic Ventilators. Anaesthesia. 17: 300 (1962). 